\title{
O MST e a reforma intelectual e moral gramsciana
}

Maria Socorro Ramos Militão

Professora da Universidade Federal de Uberlândia

\section{Resumo}

Esse estudo mostra os resultados da tese de doutorado que investiga se o Movimento dos Sem Terra (MST) contribui para a construção da hegemonia dos trabalhadores por meio da promoção de uma Reforma Intelectual e Moral, no Estado de São Paulo, visando construir uma Nuova Civiltà. O norte da pesquisa é dado pela trajetória de luta do MST e o seu significado político, tendo por base a filosofia da práxis e os pressupostos teóricos postulados por Antonio Gramsci. Pretendia-se observar se o ideário gramsciano encontra-se atuante, em que medida se tornou relevante para a práxis política do MST.

Palavras-Chave: MST; Partido; Hegemonia.

\begin{abstract}
This survey shows the results of the doctor's thesis that discusses if The Movement of the Homeless (MST) helps to build the hegemony of the workers throughout a promotion of an Intellectual and Moral Reform in the state of Sao Paulo, with the intended possibility of building a "Nuova Civilta". The focus of the survey will show the history of the fight of the MST and its political meaning based on the Philosophy of Praxis and the theoretical thinking of Antonio Gramsci. I intend to show if Gramsci's ideology is relevant today and in which way it became relevant through the political praxis of the MST.
\end{abstract}

Keywords: MST; Party; Hegemony. 
proposta desse artigo é investigar se o Movimento dos Sem Terra
(MST) contribui para a promoção de uma reforma intelectual e
moral no Brasil ao longo de sua trajetória, especialmente no Estado de São Paulo, onde tem a sua atuação. O ponto de partida de análise dessa hipótese será a própria trajetória de luta do MST, por meio da qual buscamos averiguar se em sua prática política apropriou-se e desenvolveu esse conceito gramsciano e quais os limites dessa apropriação. Busca-se averiguar, em que sentido o processo de luta, desenvolvimento e consolidação do MST contribui para a mudança de perspectiva de vida dos sem terra e quais medidas foram tomadas pelo MST para o encaminhamento dos conceitos gramscianos.

A possibilidade de um confronto entre a ideologia do MST e as categorias de Gramsci exige que averigüemos se o MST assimila a estratégia da Guerra de Posições e dentro dela o conceito de reforma intelectual e moral - via Partido Político Educador - com vistas a promover a hegemonia da classe trabalhadora, rumo à construção do socialismo, no atual estágio de desenvolvimento do capitalismo avançado. Pretende-se ainda observar os limites e avanços de construção desses conceitos para a realização de uma forma superior e integral de civilização.

A comprovação da hipótese ora proposta nos levou à análise da ação da esquerda brasileira representada pelo PCB e PT com o intuito de averiguarmos se estes partidos apresentaram um projeto político de cunho socialista para o país e se o colocaram em prática. A análise da trajetória política desses partidos mostrou que apesar deles terem sido aglutinadores e depositários das forças populares e da esquerda brasileira e de terem desempenhado importante papel na organização do operariado e dos trabalhadores rurais, não deram continuidade à essa tarefa. Isso porque, apesar do PCB apresentar um projeto de sociedade socialista para o país, a sua política de frente ampla acabou desviando-o para uma via institucional.

Já o PT não apresentou um projeto de construção de uma sociedade socialista com clareza de objetivos. O que de certo modo justifica o seu encaminhamento para o reformismo a partir do final dos anos 1980, quando 
ficaria claro que o seu único objetivo era chegar à Presidência da República. Por isso, não se apresentou como partido capaz de superar o momento espontaneísta e primitivo da imediaticidade das forças populares. O PT incorreu nesse desvio econômico-corporativo porque lutou por reformas e garantia de direitos perdendo, com isso, a possibilidade de dar unidade às greves do ABC, à aliança operário-camponesa e de aglutinar as mobilizações populares do período de democratização e que lhe deu origem, abandonando seu projeto inicial de ser o representante da esquerda brasileira e organizador de suas forças políticas.

O MST, apesar de não ser um partido político, no sentido tradicional do termo, e de não se apresentar como possível organizador da classe trabalhadora construiu um projeto de sociedade de cunho socialista e deu continuidade à proposta de organização dos trabalhadores rurais, empreendendo medidas efetivas para atingir seus objetivos propostos nos anos 1980, a partir da qual buscou desenvolver o seu projeto de sociedade socialista para o país. Por isso, construiu uma estrutura organizacional dotada de princípios que orientam a práxis política do Movimento desde a sua origem. Diferentemente do PT, que não teve por objetivo construir a unidade dos trabalhadores brasileiros nem os interesses de classe para si.

Por uma questão metodológica, dividimos a trajetória de luta do MST em cinco fases, tendo como parâmetro os cinco Congressos Nacionais realizados pelo MST. Assim, analisaremos, a partir dos seus documentos gerados, se as decisões tomadas em cada um deles foram postas em prática e, nesse processo, quais foram os avanços políticos do MST.

\section{Primeira fase da trajetória de luta do MST (1985-1990)}

A primeira fase de trajetória de luta do MST ocorreu num cenário de esgotamento do padrão de acumulação urbano-industrial iniciado nos anos 1930 e quando as lutas populares e sindicais do final dos anos 1970, especialmente nos grandes centros urbanos onde os trabalhadores exigiam liberdades democráticas, desencadearam o fim da ditadura militar. Dessas 
lutas surgiram o PT (1980), a CUT (1983) e o MST (1984), abrindo as perspectivas de mudanças que tiveram sua melhor expressão na campanha pelas Diretas já (1984).

No campo, a ditadura reprimiu as organizações camponesas, seus líderes foram assassinados, presos ou exilados, sufocando o debate e a elaboração teórica em torno da questão agrária. O governo impôs uma política de modernização da agricultura para atender a demanda urbana industrial e o mercado externo, sem tocar na estrutura fundiária, aumentando o êxodo rural, o índice de mecanização e o uso de insumos agrícolas e sementes eletivas. Foi contexto de profunda agitação política, que o MST promoveu o $1^{\circ}$ Congresso Nacional, em 1985, em Curitiba (PR), quando ainda buscava se fortalecer como movimento social, crescer e lutar pela reforma agrária. Nesse período, o MST representava os anseios dos trabalhadores rurais que, entre os anos 1979 e 1984, tinham a conquista da terra como o eixo central da luta.

As decisões tomadas nesse evento, de ocupar os latifúndios improdutivos como forma de pressão política para agilizar a Reforma Agrária foram colocadas em prática, por isso ente 1985 e 1990, o MST consolidou-se como movimento social de luta pela terra e em defesa dos trabalhadores do campo em nível nacional, expandindo-se para quase todos os Estados brasileiros e organizou os trabalhadores rurais em nível nacional. Com isso, contribuiu para dar unidade às lutas anteriormente isoladas e dispersas, e, além disso, colocou em pauta a luta pela Reforma Agrária, conseguindo avançar no processo de organização da produção nos assentamentos ao adotar o modelo de cooperação agrícola. A adoção desse modelo produtivo facilitou a organização interna da militância na base e contribuiu para vincular a produção a um projeto estratégico que organizasse os trabalhadores e liberasse quadros para a luta e resistência ao capitalismo. O modelo cooperativo apresentava-se como uma ferramenta de luta porque mostrava que a organização coletiva seria o único caminho para transformar a realidade dos camponeses brasileiros. 
No âmbito educacional, o MST desenvolveu no final dos anos 1970, as primeiras experiências com a alfabetização de jovens e adultos, fruto da necessidade de educar as crianças acampadas. Em 1989, criou a primeira escola do Movimento, em Dionísio Cerqueira-SC. Posteriormente, criou a primeira Escola Nacional de formação dos sem terra, em Caçador-SC, que seria o embrião de suas escolas de Cultura e de formação política, com o objetivo de formar militantes e quadros políticos, intelectuais orgânicos (em termos gramscianos) com o intuito de construir a hegemonia dos sem terra, preparando-os para a construção do socialismo.

Por fim, criou, nesse período, a Fundação para o Desenvolvimento da Educação Popular (FUNDEP) com o objetivo de formar professores para o MST. A partir desse momento, a educação se tornaria tão importante quanto o gesto de ocupar a terra porque o ato de educar se tornaria um aprendizado coletivo das possibilidades da vida. O elemento inovador desse sistema educacional era a apropriação da escola pública por um movimento social organizado que visa criar uma educação escolar ligada ao seu projeto social, a qual busca unir duas conquistas: "ter acesso a terra, e ter acesso à escola, ao conhecimento, à educação" (CALDART, 1997, p. 25).

\section{Segunda fase da trajetória de luta do MST (1990-1995)}

O $2^{\circ}$ Congresso Nacional do MST ocorreu em 1990, sob o lema “Ocupar, resistir e produzir”. "Ocupar era a reafirmação da forma de luta, resistir era devido à repressão, e produzir era em contestação à UDR que chamava os sem-terras de "preguiçosos e vagabundos"” (MST, 1996f, p. 12). Porém, as políticas neoliberais adotadas pelo governo contra os movimentos sociais entre 1990 e 1994, somadas à perda do apoio dos sindicatos e da Igreja, obrigaram o MST a voltar-se para o interior do Movimento e iniciar um trabalho de formação ideológica com o objetivo de fortalecer a organização interna para enfrentar a repressão. Esse isolamento estratégico levou o MST (2007g, p. 36) a organizar-se internamente, fortalecer os setores, organizar os assentamentos e acompanhamentos, 
buscar autonomia política e financeira, e organizar o Setor de Produção. Assim, se não houve avanços nas ocupações, esse momento foi crucial para investir na formação de quadros políticos, criar novas lideranças, expandir sua ideologia, consolidar o Movimento e construir a "identidade sem terra" forjada no curso da luta. Os objetivos estabelecidos foram almejados graças à clareza de que os recuos também são estratégicos na correlação de forças.

Os ganhos políticos foi, especialmente, o fortalecimento das alianças com os trabalhadores das cidades, a divulgação da luta pela Reforma Agrária e a estratégia das caminhadas pelas rodovias, que se tornariam um excelente instrumento de conscientização e de divulgação da questão agrária e cuja visibilidade faria o MST conquistar o apoio da sociedade. Por isso, passou a fazer parte de outras frentes de massa visando construir mobilizações unitárias e lutar pela unidade de forças do povo com o intuito de mudar a política econômica do governo.

No âmbito da produção, o MST investiu na produção de subsistência e em tecnologias alternativas para aumentar a produtividade, preservando seus recursos naturais e propondo-se produzir alimentos sem agrotóxicos através do uso da adubação natural da terra, em substituição ao modelo tecnológico da monocultura agro-exportadora. Criou um programa de integração da produção do campo à agroindústria, que teria como resultado a melhorias das condições de vida de 800 mil pessoas, que passaram da condição de excluídos para a de pequenos proprietários. Em 1995, elaborou o seu projeto de Reforma Agrária enfatizando que a propriedade ou posse da terra deveria cumprir sua função social: produzir para o mercado interno e não para a especulação fundiária de empresas multinacionais, bancos ou empresas.

Nesse ano, também fundou o Instituto de Educação Josué de Castro (IEJC), em Veranópolis-RS, que é uma escola de ensino médio, profissional (técnica) para a agroindústria e de formação de professores, que também se tornou um centro de formação das futuras lideranças do MST no país tendo como mantenedora o Instituto Técnico de Capacitação e Pesquisa da Reforma Agrária (ITERRA), órgão vinculado ao MST e comprometido com 
seu projeto político e pedagógico. A sua criação representou um enorme avanço para a formação técnico-profissional e para a promoção de um projeto de humanização e formação de quadros.

Esse investimento na formação técnica e política dos sem terra seria fundamental para a organização coletiva da terra e do trabalho porque, a partir de então, o problema da produção passaria a ter o mesmo grau de importância que a ocupação, já que os assentados passariam a participar da luta de massas, resultando num ganho político para o MST, que aglutinou em suas fileiras, também, os sem terra assentados.

No âmbito educacional, criou um modelo de educação classista com duas dimensões: a educação ligada ao mundo do trabalho, resgatando o valor do trabalho como meio de construir relações sociais igualitárias; e do trabalho como um método pedagógico, como construtor de relações sociais e como espaço privilegiado do exercício da cooperação e da democracia, como meio de desenvolvimento de novas relações, de cultivo de valores, de construção de novos comportamentos, de cultivo da mística nas lutas e da formação da consciência de classe.

A defesa da unidade entre teoria e prática é o ponto de confluência entre o MST e Marx e Gramsci, os quais acreditam que somente essa unidade e a aliança de classes podem elevar os trabalhadores à emancipação humana e à construção do bloco histórico socialista. Contudo, para Gramsci, a escola é apenas um dos aparelhos privados de hegemonia que contribui para a emancipação dos trabalhadores e a superação do sistema capitalista. Assim, o MST reivindicava do Estado uma escola pública planejada para o meio rural, que privilegiasse o trabalho manual e o intelectual, rompendo assim com a dicotomia entre ambos. Em termos políticos, o MST entendeu que apenas a conquista da terra não resolveria o problema agrário e se não conseguiu promover a transformação social almejada, do ponto de vista social fez com que um grande número de desempregados voltasse ao campo para tirar da terra o seu sustento. 


\section{Terceira fase da trajetória de luta do MST (1995-2000)}

O $3^{\circ}$ Congresso do MST ocorreu em 1995, tendo como lema: "Reforma Agrária: uma luta de todos" ocorreu num cenário político marcado pela adoção de políticas neoliberais, privatização das empresas estatais, desnacionalização da economia. No campo, a implantação de um novo padrão de acumulação orientada pelo neoliberalismo, aprofundou a modernização capitalista na agricultura, aumentando a exploração sobre os trabalhadores, a concentração da renda e do latifúndio, provocando o êxodo rural e o aumento as "favelas rurais" nas periferias das pequenas, médias e grandes cidades.

A partir desse evento a trajetória de luta do MST adquiriu nova dimensão política porque procurou fortalecer a organização interna e atrelou a luta pela Reforma Agrária a um projeto de transformação social, a uma luta entre projetos e de toda a sociedade. Esse avanço político foi importante para a elaboração de um Programa Agrário e para a formação de alianças de classes visando conquistar a opinião pública, ganhar expressividade e força contra seus oponentes. Assim, passou a defender a terra, a Reforma Agrária e uma nova sociedade: a posse da terra assumiria um caráter econômico; a Reforma Agrária, um caráter social mais amplo; a proposta de transformação da sociedade, um caráter eminentemente político.

Além disso, o MST identificou os desvios corporativos e economicistas no interior do Movimento e atribuía a esses desvios a causa da precariedade da formação política da militância e da debilidade da organização dos núcleos de base. Em razão disso, criou um Programa Nacional de Formação de militantes buscando fazer que todos os sem terra aderissem ao seu projeto como forma de fortalecer o Movimento na correlação de forças. Em razão disso, o MST resolver qualificar, em curto prazo, de 23 mil novas lideranças para promover a formação política da base e formar intelectuais orgânicos/quadros políticos que teriam como tarefa: intensificar o trabalho de base nos acampamentos e assentamentos, 
organizar os núcleos para diminuir a espontaneidade do Movimento; evitar o economicismo na base.

Promoveu cursos de formação técnico profissional no IEJC e desenvolveu um projeto de criação de cooperativas infantis a fim de qualificar as crianças para as diversas atividades ligadas à agricultura e desenvolver atividades formativas e educativas para o turno em que não estivessem na escola. Assim, criaria um modelo de educação infantil em dois turnos e duplamente formador, destinando à educação escolar dos sem terrinhas um período do dia, ficando o outro destinado ao trabalho. Essa educação-formativa do MST assumiria uma tripla função: intensificar a produção social; desenvolver de forma plena as potencialidades do homem; e criar meios de transformar a sociedade.

Com esse modelo de educação o MST promoveu uma inversão lógica no modo de planejar o processo pedagógico em suas escolas, pois a partir de sua elaboração, a sala de aula não seria mais vista como o único ou mesmo principal espaço educativo da escola, tampouco apenas o tempo das aulas deveria voltar-se para o planejamento escolar e para intencionalidade pedagógica. As relações sociais seriam o centro, a base de formação do ser humano - nos diferentes tempos e espaços - pois deveriam incidir sobre a atuação pedagógica fundamental.

Todavia, o maior desafio continuava sendo a erradicação do analfabetismo que, nas áreas acampadas e assentadas, atingia índices de 80 a $90 \%$, por isso o MST criou escolas de ensino fundamental e médio nas regiões ocupadas. Promoveu "massificação da luta" através de convênios e parcerias firmados com universidades e movimentos sociais visando acelerar o processo de alfabetização dos 24 milhões de analfabetos no país (conforme censo de 2000, divulgado pelo IBGE em 2003). Criou, em 1998, o Programa Nacional de Educação na Reforma Agrária (PRONERA) para formar educadores, militantes e quadros políticos. Em 2000, o resultado dessas medidas seria a construção de um modelo de educação inédito em nível mundial e a expansão das escolas do MST para 23 estados brasileiros. 
Ao compararmos os objetivos do $2^{\circ}$ e do $3^{\circ}$ Congressos, vemos que no último, de 1995, o MST enfatizava a transformação da sociedade capitalista e a construção de um novo modelo de sociedade, em lugar de defender a questão da terra como o fazia no $1^{\circ}$. Quanto à luta pela terra, não mais reivindicava que essa estivesse nas mãos de quem nela trabalha, mas que essa fosse um bem a serviço de toda sociedade, apontando para o rompimento com o modelo de propriedade e de sociedade capitalista, apesar das lutas continuarem sendo orientadas pela conquista da terra e pela promoção da reforma agrária.

\section{Quarta fase da trajetória de luta do MST (2000-2007)}

Em seu $1^{\text {o }}$ mandato (1995-1998), Fernando Henrique Cardoso promoveu um processo de privatizações, desnacionalização e sucateamento da estrutura do Estado, sem precedentes na história brasileira. O perfil neoliberal e intransigente desse governo liberou as forças conservadoras dos Estados para aumentar a repressão contra os trabalhadores rurais, resultando em dois massacres de camponeses: Corumbiara/RO (1995) e Eldorado dos Carajás/PA (1996). Contra essa política neoliberal e exigindo a punição dos responsáveis por esses massacres - que continuaram impunes - os sem terra promoveram, em 1997, uma das maiores marchas nacionais da história do país, partindo simultaneamente de três Estados (SP, MG, MT) rumo a Brasília. Cada coluna de camponeses percorreu mais de mil quilômetros, fazendo um trabalho de massificação política/debates em cada povoado e cidades por onde passavam. Na chegada à Capital Federal, mais de cem mil pessoas recepcionaram os sem terra, corroborando com seu objetivo de dar visibilidade e importância à luta pela Reforma Agrária que não mais poderia ser ignorada pelo governo ou pela mídia burguesa. Nesse período, o MST entendeu que a Reforma Agrária só aconteceria se estivesse inserida em um projeto popular de desenvolvimento do Brasil, capaz de enfrentar o modelo neoliberal, organizar os camponeses, fortalecer e ampliar a política do MST através da articulação com forças sociais. 
Assim, em seu $4^{\circ}$ Congresso Nacional, realizado em 2000, o MST reafirmaria sua luta pela Reforma Agrária e pela transformação da estrutura do capitalismo e de suas políticas neoliberais. Contando com 11 mil militantes de 23 Estados, 360 crianças na ciranda infantil e na escola itinerante $^{1}$ e com 170 lutadores de 25 países, esse evento mostrou que a influência política do MST e suas alianças se espalharam pelo mundo, reafirmando sua luta pelo socialismo.

Os objetivos tirados desse Congresso eram de cunho mais abrangente, condizentes com seu amplo projeto de superação do capitalismo. Suas novas estratégias de luta seria a "ocupação em massa", a qual deveria ser organizada em "Brigadas"2 e o apoio aos movimentos sociais brasileiros e latino-americanos. Assim, colocando em prática suas novas estratégias, o MST promoveu a segunda "Marcha popular pelo Brasil" com o apoio de várias entidades, como o de divulgar a questão agrária e convocar a sociedade para aderir ao projeto nacional popular. As Marchas e as brigadas se tornaram métodos inovadores de politização em massa e de organização política. Em Gramsci, esses dois instrumentos de politização das massas poderiam ser entendidos como escolas de cultura ou de formação política itinerante.

Durante os anos 2000, o MST desenvolve a consciência de classe dos sem terra através de cartilhas, revistas, cadernos de todos os setores, festivais de arte e cultura, boletins, livros, jornais, vídeos etc. Na visão de Gramsci, esses meios formativos poderiam ser considerados "frações de partidos", entre os quais se destaca a Editora Expressão Popular, criada pelo MST em 1999, e que se constitui numa iniciativa inovadora no país, devido ao conteúdo classista das publicações (a maior parte de autores marxistas ou

\footnotetext{
${ }^{1}$ Segundo o MST (1997d, p. 12), a criação da Escola Itinerante é o resultado reivindicação das crianças que despejadas dos acampamentos, viam-se obrigadas a repetir o conteúdo estudado anteriormente à sua chegada nos assentamentos. Aprovado pela Secretaria Estadual de Educação essa escola é um projeto pioneiro no país.

${ }^{2}$ De acordo com a Cartilha O funcionamento das brigadas do MST, “o nome 'Brigada' quer dizer a soma de partes de uma organização, para desenvolver atividades diferentes com o mesmo objetivo" (MST, 2005e, p. 5). A brigada do MST comporta cerca de 10 famílias que têm por função distribuir as tarefas entre os coletivos.
} 
que divulguem os interesse dos trabalhadores) e devido ao preço acessível ao trabalhador. Esse material educativo-formativo assume uma função orgânica essencial e pode operar como meio de construção da hegemonia.

Nesse período, o processo de formação política, iniciado com a criação do IEJC/ITERRA ganharia novo impulso, formato e se consolidaria nos anos 2000, com a criação da Escola Nacional de Formação Florestan Fernandes (ENFF). Edificada com a técnica do solo-cimento desenvolvida pela militância, essa escola proporcionou aos militantes, organizados em 22 brigadas (cerca de 1.000 trabalhadores), a apreensão de novos conhecimentos e técnicas em vários campos do saber, as quais seriam multiplicadas/disseminadas, pelas brigadas construtoras, nos assentamentos e acampamentos. A construção dessa escola contribuiu para formar intelectuais orgânicos, os quais seriam forjados pela unidade entre prática (construção) e teoria (cursos) no próprio processo de sua construção.

Os cursos oferecidos pela ENFF variam dos livres aos de pósgraduação e visam atender às demandas e necessidades do Movimento, por isso privilegiam as áreas de ciências humanas e técnicas e, em sua maioria, estão ligados à terra, à formação política, a economia e à produção. Em 2009, a escola firmou convênio com instituições de ensino médio e superior que garantem a certificação das autoridades educacionais, entre as quais se encontram 50 universidades públicas, entidades nacionais e internacionais, colaboradores e amigos de diversos setores sociais. Esses números são suficientes para comprovar a nossa hipótese de que o MST está formando intelectuais orgânicos, desenvolve o modelo Escola única e reforma intelectual e moral gramscianos e, por isso, constrói a hegemonia da fração de classe camponesa e não de toda a classe trabalhadora. Isso porque, além das dificuldades encontradas para construir a unidade e hegemonia dos sem terra, varias limitações se somariam à impossibilidade de uma única fração de classe empreender a construção da hegemonia de todo os trabalhadores. 
Quinta fase da trajetória de luta do MST (2007)

O $5^{\circ}$ Congresso realizado em 2007, contou com organização interna exemplar e com mais de 17.500 sem terras vindos de vinte e quatro Estados brasileiros, o MST anunciou um novo estágio de luta pela Reforma Agrária e pelas transformações sociais e políticas ao apresentar um projeto político amplo. Essa maturidade política adquirida ao longo de sua trajetória de luta mostrava que a Reforma Agrária só será realizada se fizer parte integrante de um projeto maior. Daí resulta a proposta de construção de um projeto de sociedade, o que implicaria em ampliar o processo de formação de quadros/intelectuais orgânicos da classe trabalhadora como tática imediata e simultânea à estratégia da ocupação de terras. Por isso, o MST promoveria a massificação dos trabalhadores e buscaria construir alianças em torno de um projeto socialista.

Nesse evento, o MST reafirmou seu projeto original de construção do socialismo e sua determinação em levá-lo adiante ao fazer um balanço dos avanços obtidos e da conjuntura econômico-política. Assim, definiu como prioridade máxima desse evento, a realização de três atividades que devem ser continuadas nos demais congressos: a realização de estudos, a formação política, e o desenvolvimento de atividades políticas e de confraternização com os sem terra e com a sociedade.

Comparando o $4^{\circ}$ com o $5^{\circ}$ Congresso, observamos que em ambos o MST mantém seus objetivos permanentes e reafirma que a luta política atual deve ser travada entre projetos de sociedade, cuja vitória será obtida pela classe que for capaz de construir ou de manter o poder hegemônico. Por causa desse entendimento o MST defenderia no $4^{\circ}$ e $5^{\circ}$ Congressos uma política de frente única entre a classe operária, o campesinato e as demais frações da classe trabalhadora, visando construir a hegemonia dessa classe pelo socialismo. Por isso, o MST continuou defendendo, no $5^{\circ}$ Congresso, o fim do capitalismo e a construção do socialismo, enquanto se como a fração de classe capaz de conduzir o processo de luta. 


\section{Considerações finais}

A possibilidade do MST contribuir para a promoção de uma reforma intelectual e moral no Brasil, ao longo de sua trajetória de luta, exige que averigüemos se esse Organismo social exerce o papel de Partido Político Educador, - intelectual orgânico coletivo - da classe trabalhadora. O qual tem a tarefa de organizar, educar e dirigir os trabalhadores no processo de construção dessa reforma intelectual e moral, a qual deve ser empreendida pelos intelectuais orgânicos na promoção da hegemonia das classes subalternas. Uma vez conquistada a hegemonia, seria possível promover a guerra de posições e construir o socialismo.

O princípio formador dos sem terra é o próprio Movimento, pois ao olhar para o MST, seus militantes compreendem melhor a sua realidade e fazem avançar as experiências de luta e de criação de um novo modo de ser, viver e ver o mundo. Por conseguinte, ser Sem Terra é mais do que ser um trabalhador que não tem terra ou mesmo que luta por ela, ser "Sem Terra é uma identidade historicamente construída, primeiro como afirmação de uma condição social: sem-terra, e aos poucos como uma circunstância de vida a ser superada, mas sim como uma identidade de cultivo" (MST, 1999b, C. E. $\mathrm{n}^{\circ}$ 9, p. 5) que projeta não uma condição, mas um sujeito social. Esta identidade fica mais forte à medida que se materializa em um modo de vida - nesse caso o dos sem terra, do MST - que projeta transformações no jeito de ser de seus militantes. Logo, a relação do MST com a formação política é uma relação de origem, pois

a história do MST é a história de uma grande obra educativa. Se recuperarmos a concepção de educação como formação humana é sua prática que encontramos no MST desde que foi criado: a transformação dos 'desgarrados da terra' e do 'pobres de tudo' em cidadãos, dispostos a lutar por um lugar digno na história. É também educação o que podemos ver em cada uma das ações que constituem o cotidiano de formação da identidade dos sem-terra do MST (MST, 1999b, C. E. n $^{\circ}$ 9, p. 5). 
De certo, diante de uma ocupação de terra, acampamento, assentamento, marcha, uma escola conquistada, o MST é o Educador coletivo desses camponeses. Mas como cada uma dessas ações educa e forma politicamente os sem terra? Como formar um ser humano de tipo novo? Que aprendizados pessoais e coletivos os sujeitos sem terra podem adquirir no MST? As respostas a essas questões são dadas pelo próprio MST na longa citação que se segue:

A herança que o MST deixará para seus descendentes será bem mais do que a terra que conseguir libertar do latifúndio; será um jeito de ser humano e de tomar posição diante das questões de seu tempo: serão os valores que fortalecem e dão identidade aos lutadores do povo, de todos os tempos, todos os lugares. É enquanto produto humano de uma obra educativa que os Sem Terra podem ser vistos como mais um elo que se forma em uma longa tradição de lutadores sociais que fazem a história da humanidade. Enraizamento no passado e projeto no futuro. A educação dos sem-terra do MST começa com o seu enraizamento em uma coletividade, que não nega o seu passado, mas projeta um futuro que eles mesmos poderão ajudar a construir. Saber que não está mais solto no mundo é a primeira condição da pessoa se abrir para esta nova experiência de vida. Não é este o sentimento que diminui o medo numa ocupação, ou faz enfrentar a fome num acampamento? Por isso para nós o coletivo não é um detalhe, é a raiz de nossa pedagogia. É, pois, do processo de formação dos Sem Terra que podemos extrair as matrizes pedagógicas básicas para construir uma escola preocupada com a formação humana e com o movimento da história. Mas é bom ter presente que a pedagogia que forma novos sujeitos sociais e que educa seres humanos não cabe numa escola. Ela é muito maior e envolve a vida como um todo. Certos processos educativos que sustentam a identidade Sem Terra jamais poderão ser realizados dentro de uma escola. Mas o MST também vem demonstrando em sua trajetória, que a escola pode fazer parte de seu movimento pedagógico, e que precisa dele para dar conta de seus desafios como sujeito educativo (MST, 1999b, C. E. $n^{\circ} 9$, p. 6).

Nesse processo de luta, a mística é parte da estrutura organizativa porque ela é o

motor que acende a paixão. Uma revolução acontece quando, apesar das condições de crise, acende-se o fogo da valorização no íntimo das pessoas, que se sentem 
geradoras do novo. É uma energia que leva as pessoas a se movimentarem voluntariamente. Faz com que tomem decisões, abram caminhos, convoquem, ordenem, realizem. Sem o fogo da mística, que aquece cada coração, não há revolução (BOGO, 2002, p. 27).

A mística é a promotora da identificação grupal e da afirmação política e social do Movimento e de cada um no Movimento. Composta pela simbologia do Movimento: hino, bandeira, foice, martelo, boné, etc. essa mística alimenta e impulsiona a luta diária porque motiva o sujeito coletivo Sem Terra em todas as ações do Movimento. Essa organização da vontade coletiva dos sem terra nasce de uma coletividade que descobre um passado comum e se sente artífice do futuro, isso porque

o sem-terra é um desenraizado que começa a criar raízes no tempo de acampamento, com a vivência da organização e a percepção da necessidade do movimento. Raízes que o tornam membro de uma grande família, de se sentir irmão ou irmã, de descobrir em si, como sujeito coletivo, a convicção de dizer com orgulho: somos Sem Terra, somos do MST (MST, 1999b, C. E. nº 9, p. 7).

Nessa perspectiva, a ocupação, o acampamento, o assentamento e a escola ajudam a enraizar a identidade Sem Terra e a formar um determinado modo de ser humano. Roseli Caldart (1997) afirma que "o grande Educador/Formador de quem nele participa ou com ele se envolve" (CALDART, 1997, p. 16), porque se constitui no pólo propulsor do despertar da luta em busca de uma nova sociedade. O MST valoriza o saber popular como forma de resgatar a identidade cultural dos camponeses, concordando com Gramsci que uma cultura é subalterna porque carece de consciência de classe. Daí a necessidade de superar o romantismo do saber popular através da sua compreensão histórica, para que possa descobrir as raízes de sua validade, na busca pela formação de uma nova Cultura. Essa nova cultura vem nascendo dos gestos e escolhas que os sem terra têm de fazer a cada dia, com efeito, a vida material é o que os impulsiona a fazer suas escolhas, construir seus valores e refletir sobre eles. Com efeito, podemos afirmar que a estratégia da ocupação de terras é a própria reforma intelectual e moral, pois com ela se inicia a crítica ao capitalismo e o 
enfrentamento às suas políticas neoliberais porque denúncia a permanência dos problemas agrários, mas principalmente porque, por meio dela o MST transforma o modo de viver e pensar dos sem terra. Na ocupação de terras, inicia-se a reforma intelectual e moral porque é a partir dela que começa uma transformação na vida dos sem terra, nela se inicia uma nova cultura, uma nova visão de mundo.

O acampamento é a forma primária de organização e luta no MST, pois ele, ou prepara a ocupação de terra ou é organizado imediatamente após esta. Nesse sentido, o acampamento é uma instancia de luta que organiza as famílias especialmente na ocupação que conduz à conquista da terra, mas é também um meio de sobrevivência e reprodução da vida social, na medida em que origina uma comunidade que desenvolve uma sociabilidade própria e que se mantém unida. A comunidade do acampamento soluciona, dentro do seu caráter de transitoriedade, vários problemas elementares da vida social, tais como a obtenção e a gestão dos recursos necessários à sobrevivência, à educação, à saúde, etc. Os limites da construção da reforma intelectual e moral do MST é que nela não está incluída a classe operária.

No Brasil, é o MST que vem empreendendo a construção da hegemonia da fração camponesa da classe trabalhadora, reafirmando o caráter contraditório da história e o valor da práxis política dos sem terra, que empreende juntamente com seus intelectuais orgânicos, a consciência de classe, a hegemonia dos sem terra e dão continuidade ao seu projeto de construção do socialismo desde a formação do Movimento. Ao contrário dos operários que apesar de serem os depositários do desenvolvimento das forças produtivas ao longo da história e das tecnologias produzidas pelo capitalismo, não constroem a hegemonia. Essa trajetória de luta do MST reafirma a atualidade do marxismo e evidencia a necessidade de se construir uma ampla aliança de classes e, acima de tudo, mostra, com sua práxis política, que é possível construir uma Nuova Civiltà, um novo Bloco Histórico - o socialista - capaz de resgatar os valores humanos e recuperar o valor da ação política e do homem como construtor e transformador de sua história. 


\section{Referências bibliográficas}

GRAMSCI, A. Alguns temas da questão meridional. In Temas de Ciências Sociais, no. 1. São Paulo, 1978.

GRAMSCI, A. A questão meridional. Trad. COUTINHO, Carlos Nelson. Rio de Janeiro: Paz e Terra, 1987. 165p.

GRAMSCI, A. Cadernos do cárcere. Vol. 1 e 2. Trad. Carlos N. Coutinho et al. 2. ed. Rio de Janeiro: Civilização Brasileira, 2001.

GRAMSCI, A. Cadernos do cárcere. Vol. 3. Trad. Carlos N. Coutinho et al. 1. ed. Rio de Janeiro: Civilização Brasileira, 2000.

GRAMSCI, A. Concepscão dialética da bistória. Trad. Carlos N. Coutinho. 3 ed. Rio de Janeiro: Civilização Brasileira, 1978. 341p.

GRAMSCI, A. Maquiavel, a politica e o Estado moderno. Trad. GAZZANEO L. M. 4. ed. Rio de Janeiro: Civilização Brasileira, 1980.

GRAMSCI, A. Obras escolhidas. Trad. CruZ, M. São Paulo: Martins Fontes, 1978.

GRAMSCI, A. Os intelectuais e a organização da cultura. São Paulo: Civilização Brasileira, 1985.

GRAMSCI, A. Poder, politica e partido. Trad. Eliana Aguiar. (Org). Emir Sader. 2 ed. São Paulo: Brasiliense, 1992. 166p.

GRAMSCI, A. Quaderni del carcere. Vols. I, II, III e IV. Edizione critica dell'istituto Gramsci. A cura di GERRATANA, Valentino. Torino: Einaudi, 2001. $3370 \mathrm{p}$.

GRAMSCI, A. Revolução e cultura. Rio de Janeiro: Civilização Brasileira, 1983. (Coleção Retratos do Brasil; v. 163).

MARX, K.; ENGELS, F. A Ideologia alemã: teses sobre Feuerbach. São Paulo: Moraes, 1984. 119p.

MARX, K.; ENGELS, F. O manifesto do partido comunista. Trad. Maria Lucia Como. Rio de Janeiro: Paz e Terra, 1996. 67p. (Coleção Leitura).

MARX, K. A miséria da filosofia. Trad. NETO, José Paulo. 2 ed. São Paulo: Global, 1985. 225p.

MARX, K. Contribuição à crítica da economia política. Lisboa: Estampa, 1973.

MARX, K. O capital: crítica da economia política: o processo de produção do capital. Volume 1. Trad. SANT"ANA, Reginaldo de. 7 ed. São Paulo: Defil, 1982. 579p. 
MARX, Karl. Manuscritos econômico-filosóficos e outros textos escolbidos. Trad. BRUNI, José Carlos. São Paulo: Abril Cultural, 1974, 215p. (Coleção Pensadores).

\section{Publicações do MST}

\section{Cadernos de educação}

Caderno de Educação no 2. Alfabetização - com escola, terra e dignidade. 3 ed. São Paulo: Setor de Educação, julho/1998a.

Caderno de Educação n ${ }^{\circ}$ 3. Alfabetização de jovens e adultos - como organizar. 1984-1999 - 15 anos de lutas e conquistas. São Paulo: Direção Nacional do MST, abril, 1994a.

Caderno de Educação n ${ }^{\circ}$ 4. Alfabetização de jovens e adultos - didática da linguagem. São Paulo: 1994b.

Caderno de Educação no 5. Alfabetização de jovens e adultos. Educação matemática. 1997: Reforma Agrária: uma luta de todos. Porto Alegre: Setor de Educação do MST, dezembro, 1996a.

Caderno de Educação n ${ }^{\circ}$ 6. Como faz̧er a escola que queremos: o planejamento. São Paulo, 1995a.

Caderno de Educação no 7. Jogos e brincadeiras infantis. São Paulo, 1996b.

Caderno de Educação n ${ }^{\circ}$ 8. Princípios de educação do MST. Reforma agrária: semeando educação e cidadania. São Paulo: Coletivo Nacional de Educação, janeiro, 1999a.

Caderno de Educação no 9. Como fazemos a escola de educação fundamental. São Paulo: Setor de Educação, novembro, 1999b.

Caderno de Educação no 10. Ocupando a bíblia. Educação religiosa. São Paulo: Setor de Educação do MST, outubro, 2000a.

Caderno de Educação $\mathrm{n}^{\circ}$ 11. Educação de jovens e adultos: sempre é tempo de aprender. 2004: 20 anos de luta por um Brasil sem latifúndio. São Paulo: Coletivo Nacional de Educação do MST, outubro, 2003a.

Caderno de Educação no 12. Educação infantil: movimento da vida, dança do aprender. São Paulo: Setor de Educação do MST, novembro, 2004a.

MST - Orientações para um trabalho infantil educativo - Setor de Educação, junho, 1998b.

\section{Cadernos de formação}

Caderno de Formação no 10. Comissão Nacional dos Assentados. Relatório do II Encontro Nacional dos Assentados. São Paulo, jun. 1986a. 
Caderno de Formação no 11 . Elementos sobre a teoria da organização no campo. São Paulo, 1986b.

Caderno de Formação no 18. Cooperativas de producão. O que queremos com as escolas dos assentamentos. $3^{\mathrm{a}} \mathrm{ed}$. São Paulo: CONCRAB, março, 1997a.

Caderno de Formação no 21. Cooperativas de produção. Questões práticas. 3 ed. São Paulo: CONCRAB, junho, 1997b.

Caderno de Formação no 22. Dicas para buscar a eficiência. 3 ed. São Paulo: CONCRAB, abril, 1997c.

Caderno de Formação no 23. Programa de reforma agrária. 2 ed. São Paulo, julho, 1996c.

Caderno de Formação no 26. A vez dos valores. São Paulo: Secretaria Nacional, janeiro, 1998c.

Caderno de Formação n ${ }^{\circ}$ 27. Mística: uma necessidade no trabalho popular e organizativo. São Paulo: Setor de Formação, janeiro, 1998d.

Caderno de Formação n ${ }^{\circ}$ 28. Pequenas histórias para entender economia politica. São Paulo: MST/CONCRAB, 1998e.

Caderno de Formação no 30. Gênese e desenvolvimento do MST. São Paulo, $1998 \mathrm{f}$.

Caderno de Formação $\mathrm{n}^{\circ} 31$. O movimento camponês no Brasil e a luta pela reforma agrária. São Paulo: Setor de Formação, janeiro, 1999c.

Caderno de Formação no 33. Latifúndio: o pecado agrário brasileiro. São Paulo, 2000b.

Caderno de Formação no 34. O MST e a cultura. São Paulo, 2000c.

Caderno de Formação no 36. O Brasil precisa de reforma agrária: as propostas dos movimentos e as "promessas e compromissos do governo Lula". São Paulo, março de 2005a.

\section{Cadernos de cooperação agrícola}

Caderno de Cooperação Agrícola n ${ }^{\circ}$ 01. O cooperativismo na china. São Paulo: CONCRAB, 1998g.

Caderno de Cooperação Agrícola n ${ }^{\circ}$ 05. Sistema cooperativista dos assentados. 2 ed. São Paulo: CONCRAB, junho 1998h.

Caderno de Cooperação Agrícola $\mathrm{n}^{\circ}$ 06. Emancipação dos assentamentos: os direitos e os cuidados que os assentados devem ter. São Paulo, CONCRAB, março, 1998 i. 